\title{
Factorial Analysis as Tool to Predict the Economic Competitiveness of Mexico
}

\author{
Juan Bacilio Guerrero Escamilla, Sócrates López Pérez, Yamile Rangel Martinez \\ School of Social Sciences and Humanities, Autonomous University of the State of Hidalgo, Pachuca City, Mexico \\ Email address: \\ bacimate@gmail.com (J. B. G. Escamilla), lopezsoc@gmail.com (S. L. Pére), yamilerangelm@gmail.com (Y. R. Martinez)
}

\section{To cite this article:}

Juan Bacilio Guerrero Escamilla, Sócrates López Pérez, Yamile Rangel Martinez. Factorial Analysis as Tool to Predict the Economic Competitiveness of Mexico. Science Journal of Applied Mathematics and Statistics. Vol. 7, No. 6, 2019, pp. 112-120.

doi: $10.11648 /$ j.sjams.20190706.13

Received: May 20, 2019; Accepted: July 12, 2019; Published: December 19, 2019

\begin{abstract}
In the present research work the essential elements are given to build the Economic Competitiveness Index (ICE) of Mexico in 2015, for which, the technique of factorial analysis of multivariable statistics is used. Of the construction of this indicator, we start with the report presented at the World Economic Forum (WEF) in 2016, in which the variables that must be considered to increase the economic competitiveness of the countries captured. With the development of this indicator, it was possible to predict the effects that technological innovation has on the competitiveness of the country. Added to this, it identifies the limitations that each federal entity has in relation to said concept. The development of this factorial model was done through the programming language $\mathrm{R}$.
\end{abstract}

Keywords: Competitiveness, Methodology and Factorial Analysis, Development of Indicator

\section{Introduction}

Nowadays, one of the essential challenges of governmental life is the generation of vital statistics, which have to be focused on the construction of relevant and appropriate data to make decisions. The development of statistical indicators has turned into the main base to know the dynamic of the behavior of certain phenomena that impinge on the mood of certain social groups.

A statistical indicator can be defined as expected value non-biased of a number sequence. Expected value or mathematical expectation is a mathematical operator that represents the median or average of a set of numbers [1]. A estimator is a non-biased if its expected value corresponds with the source parameter [2].

$$
\begin{gathered}
E(\hat{\theta})=E(X)=\mu \\
E(X)=E\left[\frac{1}{n} \sum_{i=1}^{n} X_{i}\right]=\frac{1}{n} E\left[\sum_{i=1}^{n} X_{i}\right] \\
E(X)=\frac{1}{n} \sum_{i=1}^{n} E\left(X_{i}\right)=\frac{1}{n}(n \mu)=\mu
\end{gathered}
$$

In other words, is the "tool that defines and clarifies the behavior shown of a social phenomenon, due to this definition, the operative indicators of a country are given through "the statistics which describe the behavior of the economic, social and cultural phenomena, among others [3].

"From a social context, an indicator is an element that functions to evaluate, to follow it up and to foresee trends of the situation of a country, a state or a region referred to the economy, society and human development. As well as, to value the institutional performance aimed to pursue goals and objectives focused on each one of the action areas of government programs" [3].

In the course of this research, an indicator was created to estimate the dynamic of economic competitiveness of Mexico in 2015. In order to get this, the technique of factor analysis was implemented whereby it can be obtained a statistical model.

The main aim of this research work consists of forecasting the behavior of the economic competitiveness in Mexico, taking as a reference the economic and social variables displayed at the World Economic Forum (WEF) in 2016 through the construction of the Economic Competitiveness Index (ECI) departed from the technique of factorial analysis in 2015 . 


\section{Research Methodology}

On the basis of the main objective and the fact that the construction of the Economic Competitiveness Index (ECI) should be backed up through a technique of factorial analysis, this indicator will be developed through the following methodology [4]:

1. Formulation of the model: In this first stage, the variables are put forward in the model, taking as a reference the main objective of the research as well as the theoretical basis gathered from the phenomenon being studied. As a result, it is preceded to the date search that intervene in each of the variables, where by the reviewing of different information sources is done.

2. Development of the model: This phase is constituted by stages. First of all, a correlation matrix analysis ${ }^{1}$ among the variables, thus in the way these are correlated, it would be a higher efficiency of the factors obtained. Second of all, the factors are calculated through the highest credibility ${ }^{2}$. Thirdly, the selection of factors which have to impact in the measurement of the phenomenon.

3. Validating the model: This stage is usually carried out through the fulfillment of the assumptions:

1) Factorial model fit that means that the number of factors of demand are enough to predict the phenomenon being studied.

2) The calculated factors should have zero mean and one variance.

3) The correlation among the selected factors must be invalid.

4) The factors should have one variable and invalid covariance.

4. Predicting the model: In this last stage, a rotation of factors is used (is the change of the axis of factors that is to say, they must have greater significance in its interpretation) and the gathered results are described.

\section{Problem Statement}

Since the implementation of the neoliberal model in Mexico in 1982, the economic growth of the country has been supported in the free market, this involves that task of building a context for innovation, which has been very difficult because of the slowness of the process of capitalist development. To have access to the context of technological innovation, the insertion of technologies of information and technology (TIC), it also has implied an impact on the development of new scientific knowledge; therefore, the competitiveness of technology has increased [6].

\footnotetext{
${ }^{1}$ Pearson's correlation coefficient is an indicator that measures the co-variation grade among different numeric variables related linearly [5].$$
-1 \leq r_{x, y} \leq 1
$$

Pearson's correlation ranges between -1 to 1 : if $r_{x, y}=1$, the relation is perfect positive; if $r_{x, y}=-1$, the relation is perfect negative; and if it is $r_{x, y}=0$, the correlation is invalid.

${ }^{2}$ Maximum likelihood is a habitual method which works to adjust a model and find the most efficient parameters of the sample [2]
}

The economic growth of any country is found in the free market, it will depend on certain strategies that involve the sustained use of knowledge and the creation in the center of the processes of development; as a result, these promote the economic competitiveness.

It is understood that economic competitiveness "Is the relation that exists among the used resources and obtained products, and indicates efficiency for which human resources, capital, knowledge, and energy among others are used to produce goods and services in the market" [7].

"The definition of competitiveness of nations is a field in the economic knowledge which analyzes facts and policies that determine the ability of a nation to create and keep a setting to underlie the creation of the value for the companies and greater prosperity for the population" [8].

In Mexico, the economic competitiveness in the last 25 years has been characterized due to the knowledge, allocation of bargaining power, access to social security and the alternatives to improve labor mobility [9].

According to Mexican Institute of Competitiveness (MIC) situates Mexico in the place 36 from 43 countries in 2015, having a higher concern about the levels of violence and corruption, joined to that, $57 \%$ of the economically active population is employed in the informal sector, $60 \%$ of the workers do not have pension right, and $67 \%$ of them do not have access to the health sector.

Taking into account this context, the economic competitiveness of Mexico has been declined because of various factors such as the absence of the rule of law in two of the most pernicious versions: corruption and impunity. If this not to stop, the country might be poorer, more violent and with fewer opportunities to succeed than that is today.

\section{Theoretical Frameworks}

Based on the main objective and theoretical basis of this research work is supported in the General Theory of Systems and the Techniques of Factorial Analysis.

\subsection{General Theory of Systems}

By means of this theory pursue efficiencies of the system of economic competitiveness of Mexico, to reach that, it focuses on the characteristics that encompass it such as [10]:

1. Constituting the definition and identification of the system and subsystems that are part of the competitiveness.

2. Examining the behavior of the phenomenon, considering the mathematical models taking as a reference the behavior of the systems that constitute the competitiveness.

3. Determining the degree of deviation between the real conditions and the expected ones of the system.

4. Obtaining conclusions on the known facts through the process of deduction.

Through the implementation of this theory, the performance the system as a whole of the economic competitiveness in Mexico will be implemented using the 
modeling of systems [11].

\subsection{Factorial Analysis}

It is a multivariable technique that consists of multiple simplification and complex of the relations that exist within a set of observable variables $\mathrm{X} 1, \mathrm{X} 2, \mathrm{X} 3, \ldots, \mathrm{Xp}$, through the search of common dimensions and factors. [12].

This is trying to look for a set of $\mathrm{K}<\mathrm{p}$ factors are directly observed $\left(F_{1}, F_{2}, F_{3}, \ldots, F_{k}\right)$ that explain in detail the original variables, losing the minimum data. It is relevant to mention that its capacity of data reduction and a correlation matrix is given (original variables). Its main purpose is to identify if there is a pattern of relations in such a way that can be considered as selected variables and summed up the observable interrelation of the data [13].

Mathematically the factorial model is the following:

$$
\mathrm{X}=\mathrm{LF}+\mathrm{e}
$$

Where:

1. $X$ are the original variables $\left(X_{1}, X_{2}, \ldots, X_{p}\right) \sim N(0,1)$.

2. $\mathrm{L}$ are the coefficients (strong factor).

3. $\mathrm{F}$ are the common factors

4. E are the specific factors.

Matrix form is [8]:

$$
\left[\begin{array}{c}
\mathrm{X}_{1} \\
\mathrm{X}_{2} \\
\vdots \\
\mathrm{X}_{\mathrm{p}}
\end{array}\right]=\left[\begin{array}{cccc}
\mathrm{L}_{11} & \mathrm{~L}_{12} & \ldots & \mathrm{L}_{1 \mathrm{k}} \\
\mathrm{L}_{21} & \mathrm{~L}_{22} & \ldots & \mathrm{L}_{2 \mathrm{k}} \\
\vdots & \vdots & : & : \\
\mathrm{L}_{\mathrm{p} 1} & \mathrm{~L}_{\mathrm{p} 2} & \ldots & \mathrm{L}_{\mathrm{pk}}
\end{array}\right]\left[\begin{array}{c}
\mathrm{F}_{1} \\
\mathrm{~F}_{2} \\
: \\
\mathrm{F}_{\mathrm{p}}
\end{array}\right]+\left[\begin{array}{c}
e_{1} \\
e_{2} \\
: \\
e_{\mathrm{p}}
\end{array}\right] ; \mathrm{k}<p
$$

In such a way [8]:

$$
\operatorname{Var}\left(\mathrm{X}_{\mathrm{ij}}\right)=1
$$

The variance in whatever $\mathrm{X}$ :

$$
\begin{gathered}
\operatorname{Var}\left(\mathrm{X}_{\mathrm{i}}\right)=\left[\begin{array}{cccc}
\mathrm{L}_{11} & \mathrm{~L}_{12} & \ldots & \mathrm{L}_{1 \mathrm{k}} \\
\mathrm{L}_{21} & \mathrm{~L}_{22} & \ldots & \mathrm{L}_{2 \mathrm{k}} \\
\vdots & \vdots & : & \vdots \\
\mathrm{L}_{\mathrm{p} 1} & \mathrm{~L}_{\mathrm{p} 2} & \ldots & \mathrm{L}_{\mathrm{pk}}
\end{array}\right]\left[\begin{array}{cccc}
\mathrm{L}_{11} & \mathrm{~L}_{12} & \ldots & \mathrm{L}_{1 \mathrm{k}} \\
\mathrm{L}_{21} & \mathrm{~L}_{22} & \ldots & \mathrm{L}_{2 \mathrm{k}} \\
\vdots & \vdots & : & \vdots \\
\mathrm{L}_{\mathrm{p} 1} & \mathrm{~L}_{\mathrm{p} 2} & \ldots & \mathrm{L}_{\mathrm{pk}}
\end{array}\right]+ \\
{\left[\begin{array}{ccccc}
\mathrm{e}_{1}^{2} & 0 & \ldots & 0 \\
0 & \mathrm{e}_{2}^{2} & \ldots & 0 \\
: & : & : & \vdots \\
0 & 0 & \ldots & \mathrm{e}_{\mathrm{p}}^{2}
\end{array}\right]}
\end{gathered}
$$

To the first case:

$$
\begin{aligned}
\operatorname{Var}\left(\mathrm{X}_{1}\right)= & \left(\mathrm{L}_{11}^{2}+\mathrm{L}_{12}^{2}+\cdots+\mathrm{L}_{1 \mathrm{k}}^{2}\right)+\operatorname{var}\left(\mathrm{e}_{1}^{2}\right)=1= \\
& \text { Commonality }^{3}+\text { Uniqueness }^{4}=1
\end{aligned}
$$

The Commonality is the part of variance of $X_{1}$ that is explained by the common factors and uniqueness is the part of the variance of $\mathrm{X}_{1}$ that is explained by the specific factor

The adjustment of the original variables to the factors is determined through the commonality

$\left(C^{2}\right)[14]$ :

$$
0 \leq \mathrm{C}^{2} \leq 1
$$

In such a way that:

$$
\mathrm{C}^{2}=1-\operatorname{var}\left(\mathrm{e}_{1}^{2}\right) ; \text { where } \lim _{e_{1} \rightarrow 0}\left[\operatorname{var}\left(\mathrm{e}_{1}^{2}\right)\right] \sim 0
$$

The properties of a factorial model are the following [15]:

1. The covariance matrix of the common factors is the identity matrix:

$$
\mathrm{E}\left[\mathrm{FF}^{-1}\right]=\mathrm{I} \text {. }
$$

2. The expected value of the vector of common factors is zero: $\mathrm{E}[\mathrm{F}]=0$.

3. The unique factors are correlated among them: $\mathrm{E}\left[\mathrm{ee}^{-1}\right]=0$.

4. The expected value of the vector of common factors is zero: $\mathrm{E}(\mathrm{e})=0$.

5. The covariance between the common factors and the unique factors is zero: $\mathrm{E}\left[\mathrm{Fe}^{-1}\right]=0$.

The estimation of the common factors is determined by the method of maximum plausibility, this is [2]:

$$
\mathrm{f}\left(\mathrm{X}_{1}, \mathrm{X}_{2}, \ldots, \mathrm{X}_{\mathrm{p}}\right) \sim \mathrm{N}(\mu, \sigma)
$$

Where the function of density of a normal distribution is:

$$
f(X, \mu, \sigma)=\frac{1}{\sigma \sqrt{2 \pi}} e^{-\frac{(X-\mu)^{2}}{2 \mu^{2}}} ; X \in \mathrm{R}
$$

The following criteria were implemented to select the factors to model [12]:

1. Percentage: the number of factors is taken from the $80 \%$ of the variability of all them.

2. Kaiser: the number of factors to select is considered from those where $\lambda_{i} \geq 1$.

3. Screen Plot Graphic: the number of factors to select is given when the graphic describes a cubit.

The interpretation of the selected factors might depend on the rotation of these, in other words, it functions according to the change of the reference axes at the origin until it reaches its position. This effect is implemented in the redistribution of the variance to obtain a pattern of factors with greater meaning [13]. This rotation focuses on three criteria:

1. Varimax criterion: it focuses on the maximum simplification of the column vectors of the factor's matrix. This simplification is carried out when 1's and 0 's exist in a column.

2. Quart Imax criterion: it takes into account the assessment of each original variable which a higher correlation compared with a smaller percentage of factors. In order to do this, it maximizes the variance of factorial loads.

3. Equamax criterion: it tries to maximize the average considered with the previous criteria.

The technique of factorial analysis has objectives such as:

1. To reduce the space sample of a phenomenon through the creation of new variables, which have to be nonbiased.

2. To maximize the variance of each factor, with relation to the total variance.

3. To create indicators through selected factors, and once they are joined, they take part of the Economic 
Competitiveness Index (ECI) of Mexico in 2015.

\section{Application and Results}

In this section is presented the statistical processes which were implemented for the construction of the Competitiveness Index in Mexico (CIM) in 2015. Besides this, there is an interpretation of the results obtained.

\subsection{Formulation of the Model}

The World Economic Forum (WEF), the economic competitiveness should involve the technological change, the efficiency, the real cost-saving production, and the improvement of the level of the population in general. In order to get this, it must be considered the following variables in 2016 .

Table 1. Variables that intervene in the economic competitiveness.

\begin{tabular}{ll}
\hline $\mathrm{X}_{1}=$ Corruption rate & $\mathrm{X}_{8}=$ Public investment in science and technology \\
$\mathrm{X}_{2}=$ Tax colection & $\mathrm{X}_{9}=$ Investment of companies in science and technology \\
$\mathrm{X}_{3}=$ Crime rate (number of crimes per each 100 thousand inhabitants) & $\mathrm{X}_{10}=$ Direct portfolio investment \\
$\mathrm{X}_{4}=$ Credits granted (thousands of millions of pesos) & $\mathrm{X}_{11}=$ Environment Impact (production of solid waste in thousands of tons). \\
$\mathrm{X}_{5}=$ Informal economy Rate & $\mathrm{X}_{12}=$ Economical performance Rate \\
$\mathrm{X}_{6}=$ Requested patents per year & $\mathrm{X}_{13}=$ Do business rate \\
$\mathrm{X}_{7}=$ Registered scientist in S.N.I. & $\mathrm{X}_{14}=$ Government efficiency Rate \\
\hline
\end{tabular}

Source. World Economic Forum

Based from the general objective, the Economic Competitiveness Index (ECI) will be in function of these 14 variables:

$$
E C I=f\left(X_{1}, X_{2}, X_{3}, X_{4}, X_{5}, X_{6}, X_{7}, X_{8}, X_{9}, X_{10}, X_{11}, X_{12}, X_{13}, X_{14}\right)
$$

Taking as a reference the algebraic expression 10, the effects of the variables about the economic competitiveness will be the following:

1. Greater corruption, lower competitiveness

2. Greater tax collection, greater competitiveness

3. Higher crime rate, lower competitiveness

4. Greater credit given, greater competitiveness

5. Greater formal economy, greater competitiveness

6. Greater parents requested, greater competitiveness

7. Greater number of scientists, greater competitiveness

8. Greater investment in science and technology, greater competitiveness

9. Greater private investment in science and technology, greater competitiveness

10. Greater direct overseas investment, greater competitiveness

11. Greater environmental impact, lower competitiveness

12. Greater economic performance, greater competitiveness

13. Greater business performance, greater competitiveness

14. Greater government efficiency, greater competitiveness

It is relevant to mention that with the construction of this factorial model; the necessary elements will be used to describe the behaviour of the economic competitiveness in Mexico. Furthermore, the variables with higher incidence will be identified and useful to show the dynamic of the phenomenon.

\subsection{Development of the Model}

In the chart 1 , we can observe the variables $\mathrm{X}_{1}, \mathrm{X}_{4}, \mathrm{X}_{6}, \mathrm{X}_{7}$, $\mathrm{X}_{9}, \mathrm{X}_{11}, \mathrm{X}_{12}, \mathrm{X}_{13}$, and $\mathrm{X}_{14}$ that are highly correlated. Taking as a statistical context, the correlation is presented when two or more variables are associated through Pearson's correlation.

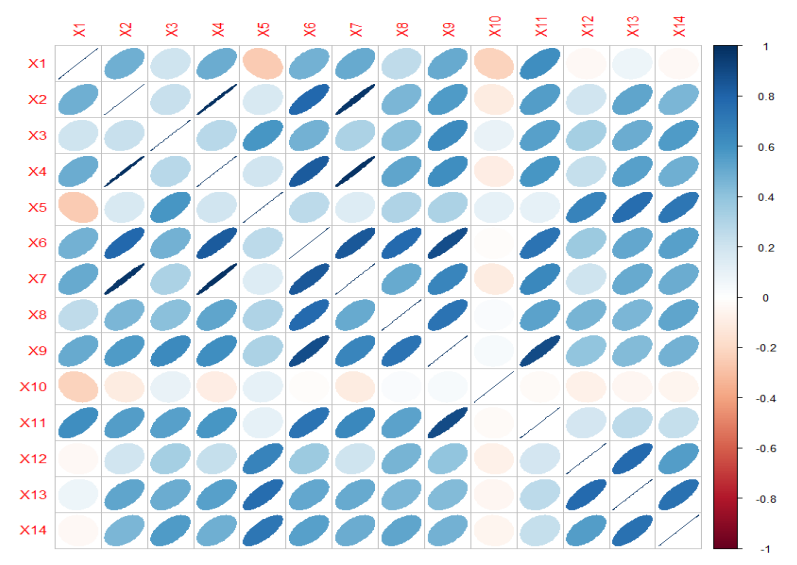

Source. Own authorship

Figure 1. Graphic Correlation Matrix.

In the graphic1, the correlation can be appreciated between $\mathrm{X}_{2}$ and $\mathrm{X}_{7}$ is so high and positive, because it ranges close to 0.90. This is the result of a sample problem due to being regular and it is presented in the models of a series of time. In this case, $\mathrm{X} 2$ makes reference to the tax collection and $\mathrm{X}_{7}$ to the number of registered scientists in the National System of Researchers (NSR) to present a high positive correlation among variables, its effect is shown as "A high tax collection, a high number of researchers in NSR". Taking as a reference, this context, it is too complicated to separate the effect that a variable produce in relation to other, as a consequence; it exists multicollinearity (shows the existence of a strong correlation among the independent variables of a model of regression [16]).

From the correlation of matrix, the calculation of factors is the following: 
Table 2. First run with 6 factors.

\begin{tabular}{|c|c|c|c|c|c|c|c|c|c|c|c|c|c|}
\hline \multicolumn{14}{|c|}{ Call: factana1 ( $x=$ ejemplo1, factors=6, rotation"varimax") } \\
\hline \multicolumn{14}{|c|}{ Uniquenesses: } \\
\hline $\mathbf{X 1}$ & $\mathbf{X 2}$ & $\mathbf{X 3}$ & $\mathrm{X} 4$ & $\mathrm{X5}$ & X6 & $\mathbf{X} 7$ & $\mathbf{X 8}$ & $\mathbf{X 9}$ & $\mathbf{X 1 0}$ & $\mathbf{X 1}$ & $\mathrm{X12}$ & X13 & X14 \\
\hline 0.375 & 0.005 & 0.288 & 0.005 & 0.005 & 0.018 & 0.005 & 0.064 & 0.005 & 0.906 & 0.048 & 0.005 & 0.146 & 0.876 \\
\hline \multicolumn{14}{|c|}{ Loadings: } \\
\hline & Factor1 & Factor2 & Factor3 & Factor4 & Factor5 & Factor6 & & & & & & & \\
\hline $\mathrm{X} 1$ & 0.371 & -0.340 & 0.506 & 0.114 & 0.170 & 0.274 & & & & & & & \\
\hline $\mathrm{X} 2$ & 0.958 & & 0.200 & 0.107 & 0.131 & & & & & & & & \\
\hline $\mathrm{X} 3$ & 0.124 & 0.512 & 0.586 & & -0.240 & -0.175 & & & & & & & \\
\hline $\mathrm{X} 4$ & 0.942 & & 0.235 & 0.170 & 0.114 & & & & & & & & \\
\hline $\mathrm{X} 5$ & 0.108 & 0.961 & & & -0.206 & & & & & & & & \\
\hline $\mathrm{X} 6$ & 0.675 & 0.117 & 0.463 & 0.537 & & & & & & & & & \\
\hline $\mathrm{X} 7$ & 0.917 & & 0.326 & 0.137 & 0.148 & & & & & & & & \\
\hline $\mathrm{X} 8$ & 0.335 & 0.176 & 0.334 & 0.688 & & & & & & & & & \\
\hline X9 & 0.376 & 0.174 & 0.778 & 0.459 & & & & & & & & & \\
\hline $\mathrm{X} 10$ & & & & & -0.290 & & & & & & & & \\
\hline $\mathrm{X} 11$ & 0.363 & & 0.890 & 0.158 & & & & & & & & & \\
\hline $\mathrm{X} 12$ & & 0.734 & 0.106 & 0.486 & 0.444 & 0.107 & & & & & & & \\
\hline $\mathrm{X} 13$ & 0.422 & 0.761 & & 0.219 & 0.188 & & & & & & & & \\
\hline \multirow[t]{2}{*}{ X14 } & & 0.327 & & & & & & & & & & & \\
\hline & & Factor1 & Factor2 & Factor3 & Factor4 & Factor5 & Factor6 & & & & & & \\
\hline \multicolumn{2}{|c|}{ SS loadings } & 3.837 & 2.619 & 2.547 & 1.361 & 0.528 & 0.159 & & & & & & \\
\hline \multicolumn{2}{|c|}{ Proportion Var } & 0.274 & 0.187 & 0.182 & 0.097 & 0.038 & 0.011 & & & & & & \\
\hline \multicolumn{2}{|c|}{ Cumulative Var } & 0.274 & 0.461 & 0.643 & 0.740 & 0.778 & 0.789 & & & & & & \\
\hline
\end{tabular}

Test of the hypothesis that 6 factors are sufficient.re sufficient.

The chi square statistic is 27.26 on 22 degrees of freedom.

The p-vaule is 1.202

Source. Own authorship

Table 3. Second run with 5 factors.

\begin{tabular}{|c|c|c|c|c|c|c|c|c|c|c|c|c|}
\hline \multicolumn{13}{|c|}{ Call: factana1 ( $x=$ ejemplo2, factors=5, rotation"varimax") } \\
\hline \multicolumn{13}{|c|}{ Uniquenesses: } \\
\hline $\mathbf{X 1}$ & $\mathrm{X} 2$ & $\mathbf{X 3}$ & $\mathbf{X 4}$ & $\mathrm{X5}$ & $\mathbf{X 6}$ & $\mathbf{X 7}$ & $\mathbf{X 8}$ & $\mathbf{X 9}$ & $\mathbf{X 1 0}$ & $\mathbf{X 1}$ & $\mathbf{X 1 2}$ & $\mathbf{X 1 3}$ \\
\hline 0.436 & 0.005 & 0.335 & 0.005 & 0.005 & 0.017 & 0.023 & 0.284 & 0.006 & 0.047 & 0.048 & 0.005 & 0.147 \\
\hline \multicolumn{13}{|c|}{ Loadings: } \\
\hline & Factor1 & Factor2 & Factor3 & Factor4 & Factor5 & & & & & & & \\
\hline $\mathrm{X} 1$ & 0.375 & 0.612 & & -0.176 & 0.109 & & & & & & & \\
\hline $\mathrm{X} 2$ & 0.953 & 0.219 & 0.110 & & 0.153 & & & & & & & \\
\hline $\mathrm{X} 3$ & & 0.350 & 0.144 & 0.680 & 0.237 & & & & & & & \\
\hline $\mathrm{X} 4$ & 0.930 & 0.238 & 0.134 & & 0.218 & & & & & & & \\
\hline $\mathrm{X} 5$ & & -0.184 & 0.532 & 0.815 & & & & & & & & \\
\hline $\mathrm{X} 6$ & 0.610 & 0.365 & 0.150 & 0.191 & 0.647 & & & & & & & \\
\hline $\mathrm{X} 7$ & 0.897 & 0.324 & & & 0.227 & & & & & & & \\
\hline X8 & 0.277 & 0.237 & 0.276 & 0.149 & 0.696 & & & & & & & \\
\hline X9 & 0.305 & 0.650 & 0.165 & 0.341 & 0.579 & & & & & & & \\
\hline X11 & 0.319 & 0.845 & & 0.245 & 0.278 & & & & & & & \\
\hline $\mathrm{X} 12$ & & & 0.953 & 0.185 & 0.218 & & & & & & & \\
\hline \multirow[t]{2}{*}{$\mathrm{X} 13$} & 0.430 & & 0.684 & 0.433 & 0.188 & & & & & & & \\
\hline & & Factor1 & Factor2 & Factor3 & Factor4 & Factor5 & & & & & & \\
\hline \multicolumn{2}{|c|}{ SS loadings } & 3.558 & 2.071 & 1.852 & 1.633 & 1.574 & & & & & & \\
\hline \multicolumn{2}{|c|}{ Proportion Var } & 0.296 & 0.173 & 0.154 & 0.136 & 0.131 & & & & & & \\
\hline \multicolumn{2}{|c|}{ Cumulative Var } & 0.296 & 0.469 & 0.623 & 0.759 & 0.891 & & & & & & \\
\hline
\end{tabular}

Test of the hypothesis that 5 factors are sufficient.re sufficient.

The chi square statistic is 25.53 on 16 degrees of freedom.

The p-vaule is 0.061

Source. Own authorship

One of the main elements in the adjustment of the factorial model is that:

$$
\lim _{e_{1} \rightarrow 0}\left[\operatorname{var}\left(\mathrm{e}_{1}^{2}\right)\right] \sim 0
$$

If the algebraic expression 11 is fulfilled, there is an adjustment. Nevertheless, it can be observed that the variables $\mathrm{X}_{10}$ (direct investment, portfolio) and $\mathrm{X} 14$ (Government efficiency) are not explanatory to predict the productivity of Mexico; thus, the variables X10 and X14 should be out of the model. Otherwise, a P- value is considered to have a 0.05 over, with six factors would be more than enough to build the Competitiveness Index of 
Mexico (CIM) (Table 2). Once the variables are taken out $\mathrm{X} 10$ and X14. In the Table 3 might be observed the remaining documents are explanatory to predict the productivity of Mexico, besides this; with a higher significance over $0.05(\mathrm{P}-$ Value of 0.005$)$, the five factors which are more than enough to build the Competitiveness Index of Mexico in 2015.

Based on the second run, the designation of the five factors will be in the following way:

"Economic Revival Index Associated to the Science (ERI)"

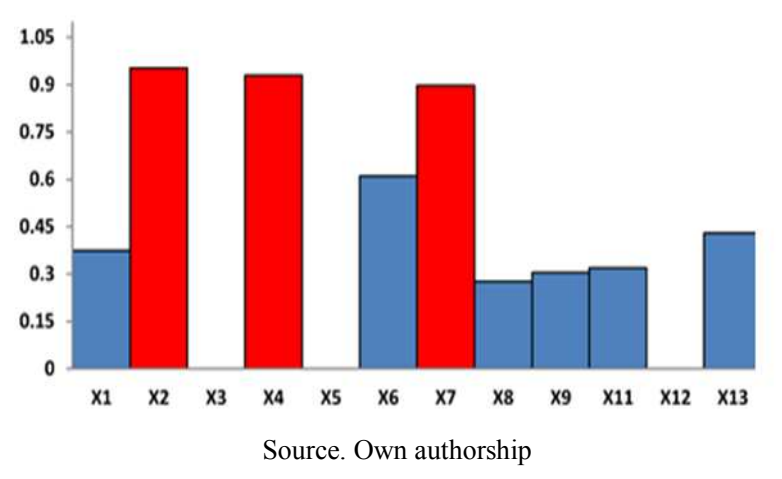

Figure 2. First Factorial.

The first factor is associated to the variables $X_{2}$ (fiscal collection), X4 (loads granted) and X7 (registered scientists NSR), and the total variability is explained about $29.60 \%$, this equates to $33.22 \%$ of the variability of the five selected factors. This factor will be called "Economic Revival Index Associated to the Science (ERI)”.

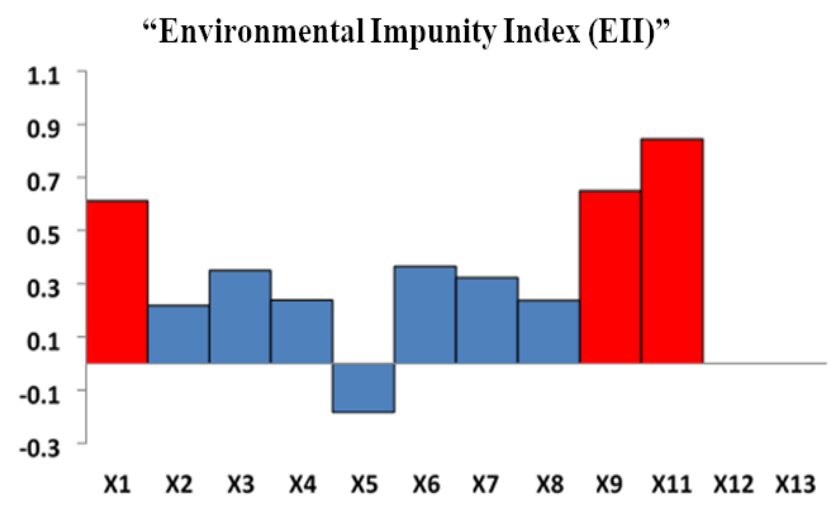

Source. Own authorship

Figure 3. Second factorial.

The second factor is associated with the variables $\mathrm{X} 1$ (corruption rate), X9 (Investment of the science and technology companies) and $\mathrm{X}_{11}$ (environmental impact level) and the total variability is explained with $19.41 \%$ of the variability of the five selected factors. This factor will be named "Environmental Impunity Index (EII)".

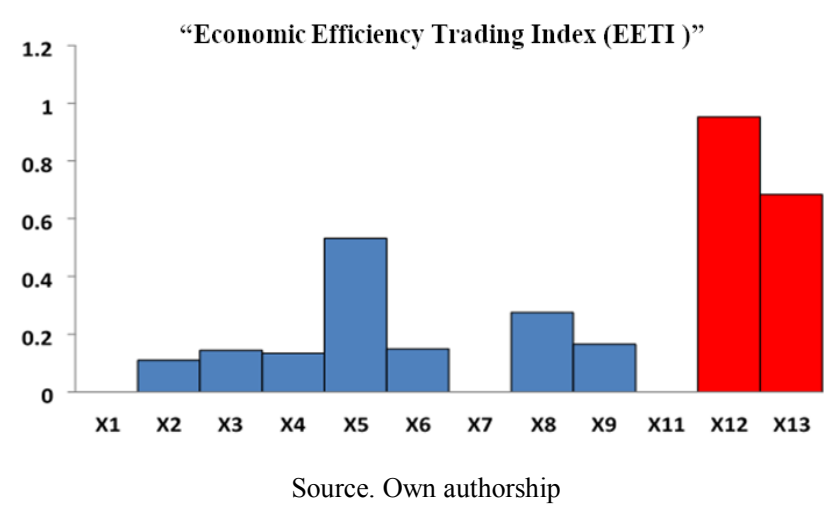

Figure 4. Third factorial.

The third factor is linked with the variables $\mathrm{X}_{12}$ (economic performance rate) and $\mathrm{X}_{13}$ (efficiency trading rate) and the total variance of $15.40 \%$ is explained, that equals to $17.28 \%$ of the variability of the five selected factors. This factor will be called "Economic Efficiency Trading Index (EETI)."

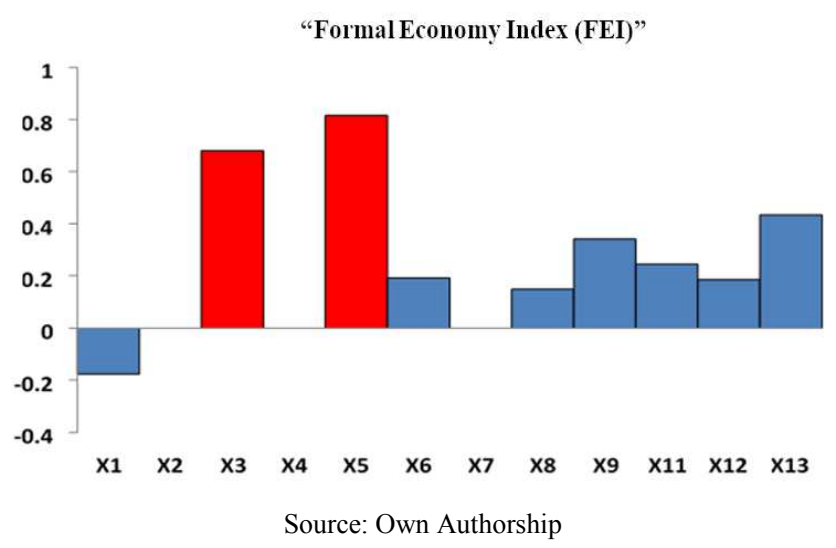

Figure 5. Fourth factorial.

The fourth factor is associated with the variables $\mathrm{X} 3$ (crime rate) and X5 (formal economy rate) and the total variability explains the $13.60 \%$, that equals to the $15.26 \%$ of the variability of the five selected factors. Thus, this factor will be called "Formal Economy Index (FEI)".

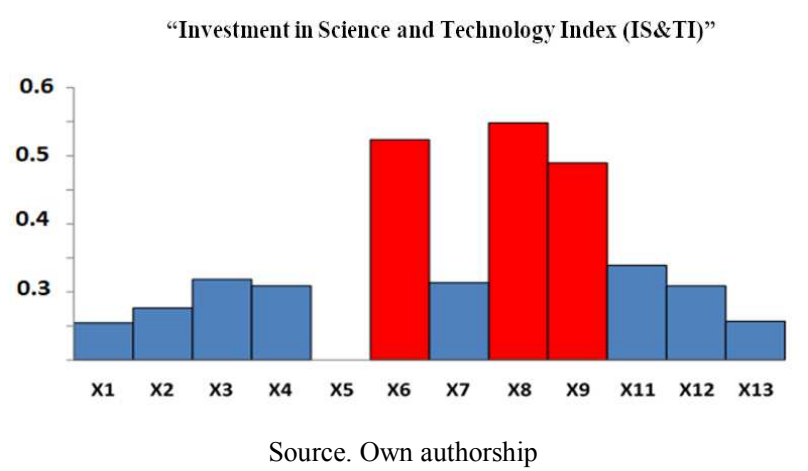

Figure 6. Fifth Factorial.

The fifth factors associated to the variables X6 (total of patents requested per year), X8 (total public inversion of science and technology) and X9 (total private investment in science and technology) and explains the total $13.60 \%$, this 
equals to $14.70 \%$ of the variability of the five selected factors. This factor will be called "Investment in Science and Technology Index". (IS\&TI).

Thereby, the Competitiveness Index in Mexico in 2015 will be the following way:

$$
\mathrm{E}(\mathrm{CIM})=\mathrm{ERI}-\mathrm{EII}+\mathrm{EETI}+\mathrm{FEI}+\mathrm{IS} \& T I
$$

Where:

1. E (CIM) is the expected value of the Competitiveness Index of Mexico.

2. ERI is the Economic Revival Index associated to the Science.

3. EII is the Environmental Impunity Index.

4. EETI is the Economic Efficiency Trading Index.

5. FEI is the Formal Economy Index

6. IS\&TI is the Investment in Science and Technology Index.

Re-ordering:

$$
\mathrm{E}(\mathrm{CIM})=\mathrm{ERI}+\mathrm{EETI}+\mathrm{FEI}+\mathrm{IS} \& T I-E I I
$$

In such a way:

1. ERI+EETI+FEI+IS\&TI are indicators that produce positive effects, in other words, the way this increase, the competitiveness will increase too.

2. EII, is a negative indicator, thus the way this increases, the competitiveness will decrease.

\subsection{Validation of the Model}

It is so important the validation to the reading and application of the factorial model, for which a set of assumptions should be fulfilled such as [17]:

The number of factors should be enough to create an indicator. The total adjustment of the model is from five factors, testing hypothesis test:

$$
\begin{aligned}
& \text { Ho: factors }=5 \text { vs Ha: factors } \neq 5 \\
& \text { If P-value }>0.05 \rightarrow \text { Ho is accepted }
\end{aligned}
$$

Once the common factors are calculated, it can be observed that P-value $>0.05$ Ho is accepted; therefore, IPM can be created with five factors and it can predict the profile of the students.

Table 4. Evidence of number of factors.

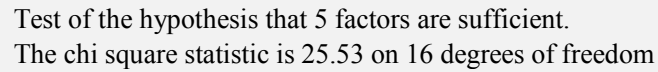

Source. Own authorship

The expected value of factors should be zero: $E(f i)=0$.
Based on the Table 5, we can observe the mean of all factors is zero; therefore, the assumption is fulfilled.

Table 5. Expected Value of the factors.

\begin{tabular}{llllll}
\hline & ERI & EETI & FEI & IS\&TI & EII \\
\hline Min & -0.961 & -1.113 & -1.006 & -1.696 & -2.342 \\
$1^{\text {st }} \mathrm{Qu}$. & -0.498 & -0.233 & -0.526 & -0.769 & -0.586 \\
Median & -0.239 & -0.092 & -0.228 & 0.114 & 0.047 \\
Mean & 0.000 & 0.000 & 0.000 & 0.000 & 0.000 \\
3rd Qu & 0.018 & -0.006 & 0.299 & 0.709 & 0.577 \\
Max & 3.131 & 5.302 & 4.514 & 2.286 & 1.921 \\
\hline
\end{tabular}

Source. Own authorship

Variance and Covariance among the factors should be one and zero: $\operatorname{var}\left(f_{i}\right)=1$ y $\operatorname{cov}\left(f_{i}, f_{j}\right)=0$.

Table 6. Variance and Covariance Matrix.

\begin{tabular}{llllll}
\hline & ERI & EETI & FEI & IS\&TI & EII \\
\hline ERI & 1.000 & 0.004 & 0.000 & 0.001 & 0.001 \\
EETI & 0.004 & 0.950 & -0.010 & -0.009 & 0.058 \\
FEI & 0.000 & -0.010 & 0.990 & 0.004 & 0.013 \\
IS\&TI & 0.001 & -0.009 & 0.004 & 0.990 & 0.013 \\
EII & 0.001 & 0.058 & 0.013 & 0.013 & 0.920 \\
\hline
\end{tabular}

Source. Own authorship

As it can be observed on Table 6, the five factors have one variable and invalid covariance; therefore, the assumption is fulfilled

The correlation among the factors should be invalid: cor(fi, fj) $=0$.

Table 7. Correlations Matrix among the factors.

\begin{tabular}{llllll}
\hline & ERI & EETI & FEI & IS\&TI & EII \\
\hline ERI & 1.0000 & 0.0037 & 0.0003 & 0.0006 & 0.0010 \\
EETI & 0.0037 & 1.0000 & -0.0098 & -0.0095 & 0.0620 \\
FEI & 0.0003 & -0.0098 & 1.0000 & 0.0037 & 0.0130 \\
IS\&TI & 0.0006 & -0.0095 & 0.0037 & 1.0000 & 0.0140 \\
EII & 0.0010 & 0.0620 & 0.0130 & 0.0140 & 1.0000 \\
\hline
\end{tabular}

Source. Own authorship

Based on Table 7 , we can observe that the assumption is fulfilled, thus all the factors of the model show the invalid correlation.

As a result, the expected value of the Competitiveness Index of Mexico E(CIM) keeps the $89.10 \%$ of the total variance. In other words, the algebraic expression 13 explains that $89.10 \%$ of how the productivity of the country will be in 2015.

\subsection{Interpretation of Results}

Through the application of the algebraic expression 13, the interpretation of the results is the following: 


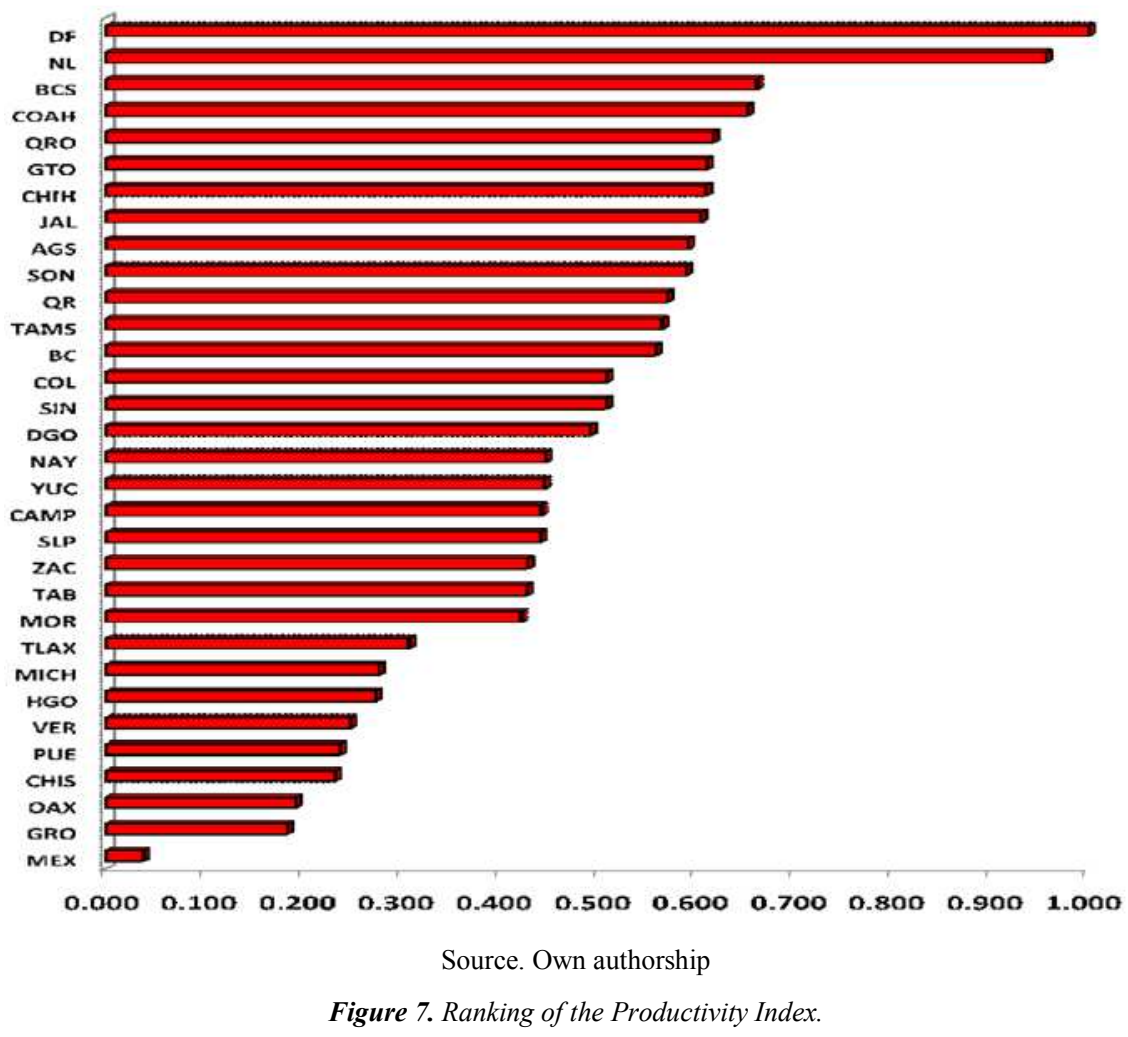

In the Figure 7, can be seen that in Mexico City (Formerly called Distrito Federal) and The Nuevo León State were of greater economic productivity in 2015, this is the result (Figure 8) of the huge concentration that entities have in relation to the institutions of higher education. As a consequence, based on the gathered results are the ones which invest the most in science and technology. In addition, the entities of Guanajuato and Jalisco are added to. On the other hand, the State of Mexico was the one that showed lower economic competitiveness, inasmuch as, and higher environmental impunity index and by doing so 32 federative entities is the one that invest less in the economic revival associated to science.

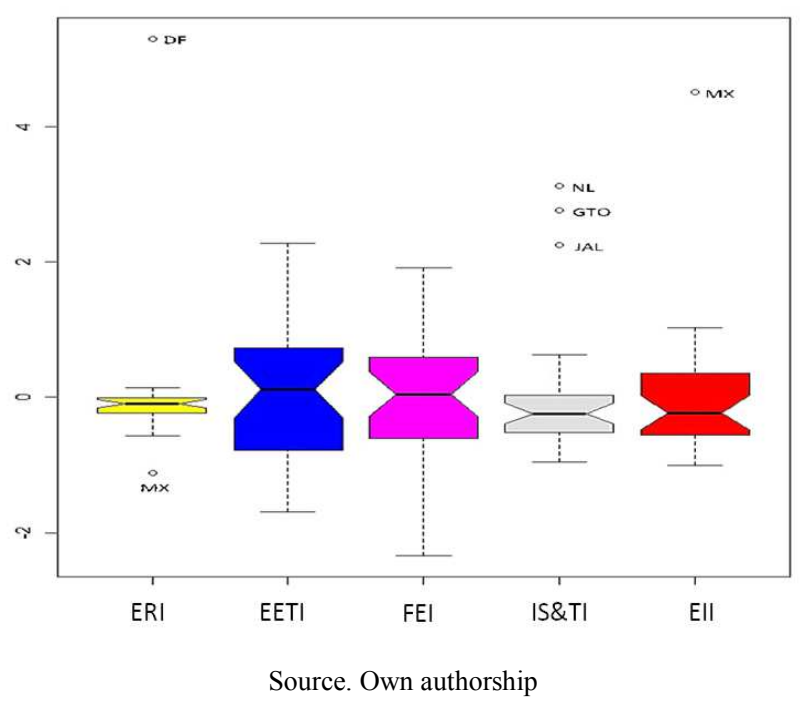

Figure 8. Box-plot by indicator.
Taking as a reference the current model has reaffirmed the importance that science and technology have within a market economy due to the innovation in different sectors such as agriculture, health, transport, energy sector among others. It is possible to reduce poverty levels and therewith the human capacities of the social groups will be increased.

\section{Conclusions}

In the development of the current research work, the following aspects must be emphasized:

1 On the basis of the General System Theory, the Economic Competitiveness Index of Mexico (ECI) is a complex phenomenon because it is based on five suprasystems: the economic reactivation associated with the science, environmental impunity, formal economy, economic efficiency trading and the investment in science and technology. Considering these suprasystems make reference of the importance that science and technology have in the economic competitiveness sector, because its effects can be considered as indirect. In other words, science and technology cause human well-being to stimulate the increase of productivity and within the economic growth and the living standards of the population.

2 This research is focusing on the importance of the mathematical and statistical tools since they allow the acquisition and consolidation of knowledge, this can be done because of a clear definition of the variables that intervene in the behavior of the phenomenon. Using the mathematical language, a social problem can be carried out into models which establish relations among the 
variables that have succeeded in other sciences. Apart from the foregoing, "the growing data availability, let to contrast with higher severity the social models into the practice through statistical methods and generate predictions and standard of behavior verifiable with the data" [12].

In summary, the mathematical and statistical models contribute to the language and the conceptual organization to provide for rules of procedure and get predictable processes of general validity. By using this, the generation of knowledge into the research is facilitated whereby might be communicated with clarity and as a result, it stimulates communication among different research areas.

\section{References}

[1] Wackerly, D., Mendenhall, W. \& Scheaffer, R. (2010). Mathematic Statistics with Applications. Cengage Learning. United States.

[2] Canavos, G. Probability and Statistics. Applications and Methods. Mc Graw Hill. México 1988.

[3] Mondragón, A. (2002). What are the indicators? Statistics Culture and Geography.

[4] Fuente, S. (2011). Factorial Analysis. Autonomous University of Madrid. Spain.

[5] Vinuesa, P. (2016) Topic 8-Correlation: theory and practice. Autonomus University of Mexico. Mexico.

[6] Ruíz, C. (2008). Mexico: Economic Geography of the innovation. Foreign Trade.
[7] Martínez, M. (2005). The concept of productivity in the economic analysis. Spanish Association of Accounting and Business Administration. Spain.

[8] Aguilar, M. The competitiveness and Indicators of Mexico. UPIICSA 2007.

[9] Cepal. (2016). Productivity and Structural Breaks in Mexico. United Nations. Mexico.

[10] Luna, P. (2005). Information and Technology Systems of Information and the Methodology DEIPHI. University of Sevilla. Spain.

[11] Sarabia, A. (1995). General Theory of Systems. ISDEFE. Spain.

[12] Peña, D. (2002). Mathematics in Social Sciences. Multivariate Analysis of data. University Carlos III of Madrid. Spain.

[13] Cuadras, C. (2012). New Methods of Mutivariate Analysis. CMC Editions. Spain.

[14] Castaño, E. (2005). Introduction to the Analysis of Mutivariate Data in Social Sciences. National University of Colombia. Colombia.

[15] Baillo, A. \& Grané, A. 100 Solved Problems in Multivariate Statistics (implemented in Matlab). Delta Publications. Spain 2008.

[16] Carmona, F. (2001). Linear Models. University of Barcelona. Spain.

[17] Alaminos, A., Francés, F., Penalva, C., \& Santacreu, O. Multivariate Analysis to Social Sciences I. Distance Indexes, Conglomerates and Factorial Analysis. Pydlos Editions. Ecuador 2015. 